\title{
THE ACUTE CONFUSIONAL STATES IN THE PSYCHONEUROSES.
}

By W. JOHNSON, LoNDON.

\section{INTRODUCTORY.}

THE frequency with which mild states of confusion have been encountered amongst the patients in an Army centre for psychoneuroses has not, as yet, received general appreciation. In the later treatment of discharged soldiers who have suffered from 'breakdowns in the line', this observation will assume a considerable degree of importance. On an average, out of some thousands of soldiers admitted to the centre (under the military term, N.Y.D.N.), about 10 per cent showed definite evidence of confusion. In the majority of these cases-about three-fourths-the confusion was of short duration, lasting twelve to twenty-four hours, and was altogether simple and transient in character. They were described in the notes under the following phrases-" appears dazed", "looks strange", " is inclined to behave foolishly", " is dull and takes no interest in anything", "does not appear to understand questions", "stares vacantly about", etc. This type may, for the purposes of this paper, be classified as the mildly confused group. In the remaining quarter of the 10 per cent the cases presented quite distinctive features, and will be described under the term the severely confused group. Here the confused state was profound, and usually persisted for from seven to ten days. For these patients a special mental ward was provided, and during the time the centre was open this ward was invariably in occupation.

\section{CAUSATION AND PROGNOSIS.}

The etiological factors concerned in these states are of a similar nature to those which lead to 'acute nervous exhaustion' or 'a breakdown' under the ordinary conditions of life. In the case of the fighting soldier, however, the immediate factors are essentially more intense, and acute strain has been borne for longer periods, than would be the case with a patient in civil life. No doubt the age, good physique, and stamina of the average soldier are responsible for this difference, as also for the rapid convalescence which was usually observed. The hereditary factor, too, which may be important in 
civil cases, is relatively insignificant in war cases, and indeed I frequently found it impossible in the case of a soldier to obtain anything in the nature of a bad family history. On more than one occasion a case has come under my observation where a man of good physique, and possessing an excellent military record, has appeared to have been completely 'broken' by the poignant character of his ordeal rather than by any inherent weakness of his own. As a rule, the way towards a breakdown has been paved by the presence of etiological factors of a less acute nature but which have acted over a long period. Such are monotony, enforced resignation to trench life, the constant assumption of a forced cheeriness as a cloak for a real feeling of anxiety and worry, with, finally, prolonged periods of irregular feeding and insufficient sleep. The importance of the toxic factor has seemed relatively to be small.

The Psychic versus the Physical Factors.-Amongst the etiological factors, emotional disturbance has, in my experience, been by far the most active. In investigating this question amongst some hundreds of cases, I found that 60 per cent were purely psychic in origin, and 40 per cent had been in the immediate vicinity of shell explosions and might therefore be considered as resulting from concussion. In view, however, of the fact that very few of this 40 per cent showed any physical sign of concussion of the central nervous system, it would appear to be difficult to refute the suggestion that in the majority of these possibly-concussed cases psychic disturbance had played the greater rôle. It will be readily admitted that in a certain margin of cases the two factors-psychic and physical-must be operative in the same patient, and therefore no accuracy should be claimed for those figures which attempt to separate cases distinctly into the two groups. Of the confused patients with which this paper deals, less than 5 per cent presented clinical evidence of concussion of the central nervous system. Doubtless many other cases were slightly concussed without any temporary paresis or paralysis being observed. The writer feels that the proportion of 7 or 8 per cent would accordingly form a generous estimate of the occurrence of physical concussion amongst these confused states. At one time an effort was made to diagnose psychic from concussion cases on the clinical evidence alone, and to confirm the diagnosis by subsequently obtaining the man's history. A certain measure of success was obtained in the extreme cases of either type, but in the majority clinical evidence by itself proved misleading. Thus, inequality of the pupils in an irritable confused patient often occurred with an entirely negative history of concussion; and in one outstanding instance a patient was admitted in an apathetic state, complaining of headache, and with a pulse-rate of 60 , where inquiry showed the man was the 
subject of a purely emotional breakdown. An examination of the tympanic membranes, and the discovery of a recent tear in one or other membrane, has occasionally been a valuable aid in the diagnosis of concussion.

In those cases which are due to actual concussion, a noticeable feature has been the relative freedom from subsequent subjective ills as compared with those which are due to emotional disturbance. In both types, however, the individual must necessarily emerge from convalescence bearing, as it were, a 'psychological scar'. In later life evidence of this damage may only be observed during times of excitement or emotional stress, and at all ordinary times the individual's behaviour may be within normal limits. Some, it must be realized, become definitely changed in character, and perhaps troubled with mild forms of obsession, which may become the bane of their existence. Thus, unless the man's earlier history be known (and this must include his pre-war, as well as his during-the-war, condition), a due appreciation of his case will not be possible. More especially one would wish to lay stress on the particular experience which immediately preceded the onset of the confused condition. This experience has frequently been one of horror and severity almost passing imagination. Examples have been frequently described, and many of them read more like fantastic tales than actual experiences through which a man has lived. It is only by full appreciation of this aspect of a case that one is able to assume the correct attitude towards one's patient.

\section{I.-THE MILDLY-CONFUSED GROUP.}

The essential points about the cases falling into this group are, as already mentioned, the shortness and mildness of the confusional state, and the rapid recovery which ensues.

1. The Simple Type.-Cases which, for want of a better term, are afterwards diagnosed as 'neurasthenia', frequently present an initial stage of slight confusion. The patients carry out simple commandssuch as putting out the tongue, etc., and, after an unduly long latent period, will answer a few simple questions, such as name, age, etc. They, however, fail completely when questions are persisted in, and are quite unable to give a connected account of themselves. They may have no knowledge of what has happened to them in the line, or of their journey down to hospital. They may supply here and there an incident, but links are wanting in the chain of events. The commonest form of amnesia is the one in which the soldier can recall events in the line until a certain thing happened, and then his memory becomes a blank. Usually he 'comes to himself' in the ambulance a few hours later. More rarely the amnesic period has been more 
extensive, and the patient has been unable to recall the events which had immediately preceded his loss of memory. Amongst my patients, it was very rare indeed to find a case where the amnesia extended into pre-war days, home life, etc.

Illustrative Case.-Pte. L., age about 25, of good physical development and appearance, was admitted in an excited and confused state. He recognized no one round him, and did not know where he was. With some difficulty he was induced to give his name. He kept looking anxiously about the ward and asking "Where am I ?" He was continually getting out of bed, but if spoken to he would return quietly. Altogether he was very irritable and troublesome. After his first night's sleep he awoke almost completely recovered, and only complained of headache. His statement then was: "I was assisting Lieut. —_ in looking after some wounded. We had had several bombardments. I went outside the dugout for fresh air, and I remember climbing the steps to get out. The next thing I knew, I found myself in bed, and wondered why they would not give me my clothes."

This patient had only been in France a few months. Apparently the sight of several wounded men had affected him deeply. Two days after admission he was doing useful work in the ward. At no time whilst he was under observation did the physical signs show any definite variation from the normal, and in fact, after the first few days, there was nothingobjective or subjective-remaining to indicate that he had passed through a period of confusion.

Treatment.-In patients presenting this simple type of acute confusion, it is not always necessary to give a sleeping draught as a routine measure. If, however, after the first two or three hours the excitement and restlessness have shown no signs of abating, a full dose should be given. As a rule, the majority of cases have settled down rapidly with absolute quiet in bed and appropriate feeding. Early movement of the bowels should be obtained. It would seem of importance that these patients should be disturbed and questioned as little as possible. Tactless examination, apart from increasing the state of excitement, may tend to focus the patient's attention on his loss of memory, or on his late experiences, and convalescence may in this way be adversely affected. After twenty-four hours' absolute rest, most patients are able to volunteer a fairly complete account of themselves. Many cases subsequently complain of various subjective symptoms, chiefly headache, buzzing sensations in the head, disordered sleep, feeling of bodily fatigue, and a marked tendency to emotionalism. Frequently the patient presents a fine tremor of the hands and an excitable pulse. These form the basis for the diagnosis of 'neurasthenia' which sooner or later is often applied to these subjects of mild confusional attacks. Further, it should be noted that owing to the mildness of this subsequent 'neurasthenic' condition, a patient is liable to meet with scant sympathy, and may be returned prematurely to duty. 
The treatment of these patients in the final stages, which was adopted in the centre, was as follows : $(a)$ Graduated physical exercises carried out twice daily for usually two or three weeks ; and following this, (b) The patient has been sent for one month's work (agricultural, etc.) in a back area, before he actually rejoins his unit. On the average, therefore, this procedure ensured that a patient who had exhibited this simple form of confusion obtained six or seven weeks in which to convalesce. One would wish to emphasize the advantage of such an arrangement as this, in which more than half the period of convalescence was spent, not at home in England, not even at the base in France, but within the Army area in the performance of useful duties.

2. Hysterical Type.-A fairly characteristic form of mild confusion is associated frequently with hysteria, and can be observed in the earliest stages before any definite hysterical manifestation has become established. The hysterical manifestation, one must remember, is, after all, only the expression, and not the substance, of hysteria, which is constituted by the abnormal mental attitude of the patient. Seen in the earliest phase, the patient usually lies quietly in bed with his head under the clothes. His desire is to lie undisturbed and hidden, and, if interfered with, he is inclined to be resentful, and will sit up glaring about. Repeated efforts are necessary to induce him to perform simple movements, such as closing his eyes. He gives one the impression of having understood what is asked of him, but refusing to carry out the action. When eventually he does obey, his actions are incorrect. Instead of closing his eyes, he blinks spasmodically, or puts his face through a series of contortions. Frequently he will break off in the middle of his movements, lie down in bed, and abruptly turn on his side. As a rule, a single night's rest is sufficient to dissipate this attitude, and the patient then becomes the ordinary hysterical type, presenting mutism, coarse tremor, paresis, or paraplegia, as the case may be. Less frequently the confused state is somewhat deeper, and the patient appears not to understand anything said to him. The result of disturbing him is to cause him to shriek out, and to produce a severe outbreak of emotionalism (passionate weeping, etc.), which is often associated with the revival in his mind of some harrowing experience. Such cases usually take four or five days before anything approaching normal emotional control is regained, and, the patients have later proved themselves to be exceptionally emotional individuals by nature.

Illustrative Case.-Gunner M., age about 27, a man with inferior physique. He lay in bed with his head under the blankets. When one uncovered his head, his gaze became fixed, and he had the appearance of witnessing some terrifying spectacle. This lasted for a few minutes, and 
he then broke into loud weeping. He only appreciated questions when these were shouted loudly. He could neither speak, sit up, nor walk. When placed on his feet he collapsed limply, rolled on the ground, and then assumed a position of opisthotonos. On relaxation occurring, a mere touch was sufficient to reproduce this state of opisthotonos. Repeated attempts were necessary before his attention could be secured, and he soon relapsed again into his state of fixed staring. Gradually his attention was obtained for longer and longer periods, during which his mutism and paraplegia were treated stage by stage. He returned to the ward able both to speak and walk.

Treatment.-The above case will serve to illustrate the wisdom of allowing a patient time to recover from the confused state before undertaking the cure of his hysterical symptoms. In this particular instance the case was treated at the expense of much greater stress to both doctor and patient than would have been necessary later. In such cases a delay of three to four days with the patient in a suitable 'ward atmosphere' should invariably be made. The danger of provoking an emotional outburst during treatment will then be found to be practically nil, and hysterical manifestations can be dispelled with much greater ease.

\section{II.-THE SEVERELY-CONFUSED GROUP.}

As a rule the patients in this group were men with long fighting service, with a past history of wounds and sickness or of having been blown over by shells. In a certain number where this history was not obtained, and the soldier had only a few months' service to his credit, it was found either that a previous breakdown had occurred in civil life, or that the patient was young and of such a type temperamentally that he would obviously not sustain the conditions in the fighting area for long. In many cases, too, reports were received stating that a change had been noticed in the man's behaviour with his unit for some time past; that he had become unreliable and gloomy; as a rule he had been restless, unable to sleep, and, whilst in the line, frequently parading sick with complaint of severe headache.

On Examination.-The general appearance was one of exhaustion, the patient usually being in poor physical condition. There was fine tremor of the hands, over-action of facial expression, a state of general sweating, rapid pulse (100 to 120), exaggerated tendon reflexeś, cutaneous hyperæsthesia, and an irritable reaction of the pupils to light. Occasionally an opposite condition was observed. The tendon-jerks were diminished, cutaneous sensation was dulled, and the pupillary reaction to light was slowed. This state usually indicated that the condition of confusion had already lasted several days. I examined the urine in many cases, and never found the presence of sugar or albumin. 
1. The Shorter Type.-The cases falling within this subgroup seem, on account of their transient character, to come appropriately under the term, 'exhaustion psychosis'. They, however, exhibit an acute confusional state of a more profound nature than those described under Group 1, and one which lasts three, four, or even five days. When seen within a few hours of the onset, the patient is wildly excited, and will not remain in bed. He keeps up a constant muttering, snatches of which are intelligible, and are found to refer to his late experiences in the line. He occasionally shouts out loudly, and trembles with terror, or bursts into tears. No coherent answer can be obtained to questions, although his attention may be gained sufficiently at times to obtain some form of reply. He does not recognize the fact that he is in hospital, nor does he appreciate the identity of those around him. He appears to be living again through his recent experiences in the line, and interprets anything occurring near him from this point of view. Those near him are comrades in his unit, whom he addresses by name and talks to continually. Or they are German snipers, etc. Frequently he will sit up suddenly in bed and, with a terrified look on his face, shout "Look, look!" Then he will sink back in bed, moaning a friend's name. Any noise occurring near is thought to be bombs, shells, machine guns, etc., and is liable to bring on one of these brief outbursts. Towards the third or fourth day the patient's state of confusion has usually markedly decreased. He can then give some account of himself, his unit, and of what happened to him in the line. There is frequently, however, a complete blank in his memory, which may be partially filled later, but in not a few cases certain episodes in the recent memory have been permanently lost. At the end of ten days or so he will have improved so much that constant supervision on account of the 'wandering tendency' will no longer be necessary; whilst towards the end of the third week there will appear to be very little wrong with him. Subjectively, he may then complain of headache, dizziness, palpitation, irritability, a sense of undue fatigue, nightmares, or irregular sleep. Many tend to worry over the past amnesic state, or have a dread of mental disorder. At this stage patients were evacuated to the base, and their subsequent history is not known.

Illustrative Case.-Pte. C., age 19, boyish in appearance. The notes received from Capt. D. Bird, R.A.M.C., medical officer to his unit, stated : "He was sent to the regimental aid post for his strange behaviour. At first he answered questions by nodding or shaking his head. When given food he crumpled it up and dropped it on the floor, and when given a jug of water he poured it over himself. He is very restless, and will not sit in one place for more than a few minutes, then gets up and wanders round in a half-dressed condition. Temperature is normal, pulse 120, and tendonjerks are exaggerated."

vol. I.-NO. 2 . 
When he came under my observation a few hours later, he was highly excited and deeply confused. He had no idea where he was, and it was impossible to get any information from him. He was continually trying to get out of bed. A little later he became very emotional, weeping and shouting aloud, repeating anything he heard said. He was continually spitting about the floor. Next day he supplied one or two details about his home in Bradford, but could give no account of his recent experiences. Careful watch was still necessary to keep him in bed. He slept indifferently for the first three nights, but after that obtained almost twenty-four hours' continuous sleep. On the fifth day he was quite quiet and talking reasonably. Appetite good. Pulse 96. When evacuated to the base, he was still inclined to be emotional and was somewhat irresponsible in manner.

2. The Longer Type.-In these cases the depth and duration of the confusion seem to warrant their being grouped under the term 'acute confusional insanity'. At the end of two or three weeks the patients still showed signs of confusion, persistent hallucinations, ideas of persecution, etc. They had accordingly to be evacuated to the base as mental cases. On admission, the patient was usually in such a wildly excited condition that he required tying into bed. He would continue to struggle and shout for sometimes two to three days. He was, as a rule, suspicious, and presented a dangerous demeanour. His talk would be full of some real or supposed injury to himself. He would take no notice of questions, and his talk was all concerning the subject on his mind-e.g., "You are the one", "You are a German in disguise", "Will they shoot me?" etc. He would hear voices outside, and shout that everyone was plotting against him. Another patient would believe that the ward was an entrenched position, would picture machine guns here and there, and chatter about the fighting, calling out orders in a firm voice. This violent acute stage usually terminated towards the end of a week, leaving the patient in a somewhat apathetic condition, in which he lay in bed muttering to himself. His hallucinations and false ideas would still, however, be active, and frequently there was a brief recurrence of the excited state, followed by a temporary relapse into marked confusion. At the end of three weeks the patient usually presented a slow manner and a gloomy demeanour, with a marked tendency to be secretive and suspicious. When evacuated in this condition to the base, many cases were definitely delusional.

Illustrative Case.-Pte M., age about 21, of average physical development. The notes received from Capt. W. Power, R.A.M.C., stated : "This soldier was admitted to field ambulance in a restless and excited condition. His temperature was $\mathbf{9 9 \cdot 4 ^ { \circ }}$. Next morning he appeared to be very nervous, and told me a long story about getting married. Three days later he suddenly began to be troublesome, and was continually wandering away from the ward. On the fifth day he was more excited, and stated that the ward orderly was impersonating him, and that his father was outside waiting for him. The slightest noise made him start, and look about in 
a terrified manner. On another occasion he shouted out that he was Capt. Hamilton, and threatened to put certain persons under arrest. He was, however, never quite unmanageable".

On the tenth day he came under my observation. He was in a very terrified state of mind. His expression was staring and anxious. He talked rubbish in reply to questions. When left alone, he would lie for hours with his head covered up, muttering to himself. Thẻre was a slight general tremor of arms and legs. Restlessness was very marked, and a great difficulty was experienced in keeping him in bed. On the fourteenth day his condition had become much quieter. He still wanted "to get on with his journey to Deal ", and required careful watching. Occasionally he had brief attacks of weeping, following which he would suddenly become quite cheerful and talkative. His appetite was very variable. He slept very lightly, and waked up frequently. On the eighteenth day his condition was as follows: Complains of headaches. His attention is very poor, cerebration much slowed, and he still exhibits terror both in his appearance and behaviour. He stutters occasionally, and is continually asking to be allowed to go. The hands show a fine tremor. Pulse 120. Tendon-jerks much exaggerated. Pupils equal, and react sluggishly to light and accommodation. A few days later he managed to get away, and walked up to a post just behind the line. After being returned to hospital he continued to act in an irresponsible manner, until he was eventually evacuated to the base.

Treatment.-The patient must be kept in bed as long as his confusion lasts, and forcible means must be used, whenever necessary, to keep him quiet. Regular feeding, free movement of the bowels, and the early securing of sleep by every means in one's power, should be ensured. Putting the patient in a separate tent away from all other patients is advisable, if this can be done. In the first few days I found that immersion in a bath at a temperature of $103^{\circ}$ to $105^{\circ}$ for half an hour daily (or every twelve hours if necessary), followed by the administration of chloral hydrate and potassium bromide, or paraldehyde or veronal, has been a useful routine measure for quieting the excitement and inducing sleep. Whilst in the bath the patient's pulse should be watched. As a rule it has seldom been necessary to administer hyoscine hydrobromide, and all soporific drugs are withheld as soon as the patient's state permits. Hot wet packs have not proved as beneficial as the immersion of the patient in a hot bath.

Much difficulty was experienced in feeding the cases in this group. They either took little or no interest in their food, or else refused it altogether. On the second or third day, therefore, forcible feeding was not infrequently called for. Alcohol, one need hardly say, should be absolutely avoided. It is possible that in some cases the confusional state had been accentuated by its use. I have notes of one case where an acutely delirious state followed shortly after the patient had been given " a stiff whisky in order to pull him together". This man was exceedingly violent on admission. 
In the last stages, when confusion is passing off, I have found that a dose of potassium bromide occasionally at night has been effective in treating the minor sleep troubles.

\section{MISCELLANEOUS GROUP.}

A few patients were admitted with varying degrees of confusion in whom eventually a diagnosis of definite mental disorder was established. Such conditions were: mental deficiency, dementia, general paralysis of the insane, acute mania, manic-depressive insanity, delusional insanity, and melancholia. One or two cases of dementia præcox and paranoia were also observed.

Three cases of an uncommon form of mental torpor were admitted, and deserve some description. At first they were regarded as being either hysterical or malingering, but close observation over a prolonged period sufficed to exclude both these conditions. The patient lay in an apathetic state in bed, with apparently complete suspension of all psychic functions. Depriving him of his meals produced no reaction. There was no incontinence of urine or fæces. When spoken to, he evinced no interest, and either gave no answer at all, or muttered "I don't know". If given food, however, he took it in the ordinary way. Physical examination showed no noteworthy change from the normal state.

Illustrative Case.-Pte. S., age 23, stolid, robust appearance. On admission, he presented a dazed, lethargic condition. He lay in bed with his face pressed against the pillow, and rarely changed his position. If rolled on to his back, he lay with his eyes closed, and made no resistance. After much persuasion he opened his eyes and glared round, with apparently no evidence of recognition in his expression. All questions and the ordinary means of rousing (shaking, etc.) produced no result; all psychic activity appeared to be suspended. After four or five days-during which time he had lain most of the time like a log-he began to look round a little. When asked how he felt, he stared hard at one for several seconds, and then answered in a low tone, "I feel better". He volunteered no conversation himself, accepted passively anything which happened, and had not appreciated the fact that he was in hospital. After eleven days he began to walk aimlessly up and down the ward, but took no notice of other patients, and never spoke to anyone. He was put for a few days on a pure milk diet, but this called for no protest. After taking him to a concert in the hope of rousing him, practically no change occurred in his condition. On the seventeenth day his condition was as follows: Strong frowning expression, which is persistent. Slight twitching movements of the orbiculares palpebrarum. Tongue tremulous. Attention is only obtained with the greatest difficulty, and goes again at once. He answers simple questions after a delay of several seconds. During the whole time he has been in the ward he has made no complaint of any kind, and no account of his history-recent or remote-has been obtained from him. His habitual attitude now is to sit with his head buried between his hands. 
Physical signs of the nervous system show no evidence of organic disorder. Urine : sp. gr. 1020, acid reaction, no sugar, no albumin. This patient was evacuated to the base during the fourth week of his condition.

In another patient $I$ found no improvement had occurred at the end of six weeks.

\section{CONCLUSIONS.}

The states of confusion so intimately bound up with the earliest stages of the psychoneuroses have been found to be not infrequent in an Army centre dealing with these patients. The rough classification used in this paper has been adopted in order to lay stress on the fairly distinct grouping which was observed. The cases appeared to group themselves into three fairly distinct types: (1) Simple type with short confusional period; (2) Severe type with pronounced, but temporary, state of confusion; (3) Type associated with definite mental disorder. The majority of cases fell into Group 1.

The character and relative frequency of these confusional states deserve the consideration of all who are now engaged in the treatment of soldiers suffering from psychoneuroses. They serve to throw light on symptoms which otherwise appear unaccountable, and help to explain the instability which many patients still exhibit in an obstinate degree. It is only by an appreciation of the fact that many cases-which are now being treated for vague subjective symptoms, mild forms of mental incapacity, etc.-have undergone definite periods of confusion in the early stage of their disorder, that proper prognosis and treatment become possible. 